STUDI

FRANCESI

\section{Studi Francesi}

Rivista quadrimestrale fondata da Franco Simone

190 (LXIV | I) | 2020

Varia - fasc. I - gennaio-aprile 2020

\title{
LAURE FAGNART, Léonard de Vinci à la cour de France
}

\section{Paola Cifarelli}

\section{(2) OpenEdition \\ Journals}

\section{Édition électronique}

URL : https://journals.openedition.org/studifrancesi/22451

DOI : 10.4000/studifrancesi.22451

ISSN : 2421-5856

\section{Éditeur}

Rosenberg \& Sellier

\section{Édition imprimée}

Date de publication : 1 avril 2020

Pagination : 161-162

ISSN : 0039-2944

\section{Référence électronique}

Paola Cifarelli, « LAURE FAgnaRt, Léonard de Vinci à la cour de France », Studi Francesi [En ligne], 190 (LXIV | I) | 2020, mis en ligne le 01 avril 2020, consulté le 02 août 2021. URL : http://journals.openedition.org/ studifrancesi/22451; DOI : https://doi.org/10.4000/studifrancesi.22451

Ce document a été généré automatiquement le 2 août 2021.

\section{(c) (†)}

Studi Francesi è distribuita con Licenza Creative Commons Attribuzione - Non commerciale - Non opere derivate 4.0 Internazionale. 


\title{
LAURE FAGNART, Léonard de Vinci à la cour de France
}

\author{
Paola Cifarelli
}

\section{RÉFÉRENCE}

LAURE FAGNART, Léonard de Vinci à la cour de France, Rennes, Presses Universitaires de

Rennes, 2019, 275 pp.

1 Ce volume richement illustré est destiné essentiellement aux historiens de l'art, qui pourront trouver une série d'hypothèses, corroborées souvent par les documents d'archives, concernant l'entrée des tableaux de Léonard dans les collections des rois de France, leur parcours dans les périodes successives, les conditions de conservation dans les demeures royales. Cependant, l'intérêt pour tous les spécialistes de la Renaissance réside dans l'exploration des rapports qui lièrent le maître aux rois de France, Louis XII et surtout François $\mathrm{I}^{\mathrm{er}}$, ainsi que de ses engagements auprès d'eux et des autres princes contemporains. Comme l'A. le précise dans l'introduction, le présent ouvrage s'appuie sur la monographie qu'elle avait publiée en 2009, dont les points qui concernent les œuvres de Léonard entrées dans les collections des rois de France ont été sélectionnés, précisés et augmentés, particulièrement pour ce qui est des rapports entretenus avec les monarques du vivant de l'artiste.

2 L'ouvrage se structure en quatre chapitres organisés chronologiquement et couvrant une période allant de la conquête du Milanais par Louis xii jusqu'au règne de Louis xiv, avec l'aménagement du château de Versailles.

Dans le premier, l'A. explore les premiers contacts de l'artiste avec les Français, dont elle suppose qu'ils concernent surtout des ouvrages d'ingénierie; elle rappelle ensuite l'admiration du roi pour la Cène milanaise, témoignée en 1526 par Paolo Giovio, pour essayer de déceler la part de vérité inscrite dans un épisode topique. Les copies de la fresque possédées par Antoine Turpin, trésorier général du duché de Milan, et par le cardinal Georges d'Amboise, principal conseiller du monarque en seraient autant de 
preuves indirectes et indépendantes. Tout un réseau de rapports se dessine, à partir de ces premiers contacts, dans les années suivantes, impliquant le lieutenant Charles II d'Amboise, neveu du cardinal, dont on analyse les échanges épistolaires avec la Seigneurie de Florence en 1506, puis Francesco Pandolfini, ambassadeur de Florence auprès de la cour de France, qui fournit des témoignages à propos d'ouvrages d'ingénierie et de peinture; les tableaux qu'auraient possédés autrefois Florimond Robertet et d'autres hauts fonctionnaires du royaume, ainsi que la correspondance intense de la diplomatie française avec les représentants de la seigneurie de Florence et quelques brouillons de lettres de Léonard conservés jusqu'à nous témoigneraient de ces contacts intenses dans la première décennie du XVI e siècle. Pareillement, l'histoire de tableaux célèbres, tels la Vierge aux rochers, atteste l'engouement de Louis XII pour les ouvrages du maître.

4 Le deuxième chapitre, consacré à «François I ${ }^{\text {er }}$ et Léonard», rappelle des faits connus en précisant leur chronologie et retrace l'activité intense dans le domaine du dessin, de l'urbanisme et du génie civil du maître italien. Les étapes de la construction de Chambord, la conception hypothétique d'automates, l'organisation de fêtes de cour, la systématisation de ses écrits et les événements ponctuant la période française de Léonard sont décrits ici en faisant souvent référence aux documents authentiques (dessins, lettres, relations); certes, la rareté des pièces comptables et autres témoignages permettant de détailler avec précision ces activités oblige l'A. à rester souvent au niveau de la formulation d'hypothèses. Il en va de même pour les achats effectués par le monarque en 1518, comprenant entre autres la Joconde. Ce manque de documentation concernant plus généralement les contacts de Léonard avec les intellectuels, les peintres et les hommes de lettres contemporains lors de son séjour à Cloux est également l'élément qui laisse les spécialistes de littérature et de culture françaises un peu sur leur faim. Il n'en reste pas moins que le grand intérêt de la cour pour l'activité artistique de Léonard ressort de manière évidente, entre autres par l'analyse de la riche symbolique de la tapisserie représentant la Cène de Santa Maria delle Grazie, réalisée à l'intention de Louise de Savoie et de François I ${ }^{\mathrm{er}}$, ou celle des tableaux de chevalet qui devaient orner l'appartement des bains au château de Fontainebleau.

5 Les chapitres trois («Sous Henri IV et Louis XIII») et quatre («Le règne de Louis XIV») décrivent les efforts déployés par les monarques pour protéger et mettre en valeur les chefs-d'œuvre de Léonard, ainsi que pour accroître les collections royales, témoignant ainsi de la continuité de l'intérêt des rois de France envers cet artiste exceptionnel.

6 La bibliographie réunie à la fin du volume constitue un excellent point de départ pour tous ceux qui voudront approfondir les questions encore ouvertes, ou étendre l'exploration aux domaines autres que l'histoire de l'art. 